\title{
EQUITY IN ADMISSION: COMPARATIVE STUDY OF SECONDARY DATA IN HIGH SCHOOL CURRICULUM VALUATION
}

\author{
Salma Sadia Rakhman, Zeenath Reza Khan
}

\begin{abstract}
A student's journey from high school to university begins with the admission department evaluating their credentials. Worldwide school curriculum varies in terms of syllabus, structure, assessment methodology and learning outcomes. This variation in pre-university curricula imposes the challenge of equally benchmarking them in providing university admission. The challenge extends beyond the initial admission process due to existence of improper valuation of quality of students, which co-relates to academic performance and misconducts. So how do universities go about providing admission to students from varied curricula? This study tracks the admission requirements of five local accredited universities in the United Arab Emirates to demonstrate the importance of equity in admission.
\end{abstract}

Key words: Admission Criteria, Equity, Benchmarked Criteria, Valuation, High School, Curriculum

\section{Introduction}

Education is an essential integrated part of society which provides knowledge, morality and integrity of an individual. The pathway from high school to university is a crucial journey that differs nationwide in terms of different pre-university curriculum adopted by different countries across the globe. Each curriculum entails distinctive course content, structure and assessment criteria defining an individual's credentials through certification. Gudo and Olel (2011) postulates in their study the admission equivalency associated challenges encountered due to globalization and cross-border mobility of students across the globe. This provides the platform for evaluating with the use of secondary data in understanding how universities across the United Arab Emirates (UAE) equalize high school qualification for admitting students. Aidoo-Buameh and Ayagre (2013) suggested in their study that there exists lack of consideration of quality of students taking admission in university. This absence attributes to evaluation of student performance at undergraduate level which sets the platform of this research. Additionally, the correlation of admission criteria to academic performance leading to practice of academic misconduct is an objective of this research.

A comparative study about university students engaging in academic misconduct in the United States of America (USA) and the UAE by Williams et. al. (2014) reported that $70 \%$ and $73 \%$, respectively, of business faculty students have engaged in some academic misconduct activities. Even though the study considered business students only; the figure $73 \%$ evokes the importance of considering proper valuation and set standard criteria to be identified for recruiting well-informed students about academic integrity along with outstanding academic performance to university programs. Furthermore, Tabsh et al. (2015) stated in his study regarding responsibility of universities 
to ensure academic integrity along with student success in academic performance. Along with that emphasizing how academic dishonesty specifically in undergraduate programs has become a significant issue (Tabsh et al., 2015). In their exploratory study, (Harding et al., 2004) demonstrated similarities in the decision-making process associated to participation in professional dishonesty due to prior involvement in academic misconduct at college level. Academic dishonesty results in substantial consequences for society in general. The "Theory of Planned Behavior" elaborates the correlation among future behaviors to prior behaviors. Similarly, several studies highlighted engagement in academic dishonesty as a prior deviant behavior which is demonstrated in future deviant behaviors in terms of tax evasion, dangerous driving, alcohol abuse, embezzlement, etc. causing significant distress in society. Therefore, policy development to ensure academic integrity is essential to eliminate such negative notions in professional level and in society. To begin with at university level; it is the responsibility of the university to support all students in meeting the academic integrity. Universities incorporating multi-cultural and students from diverse high school background are required to advocate a holistic approach ensuring fairness, equal opportunity and understanding of the appropriate conventions (Atkinson et al., 2016).

As such, a student's journey to university starts from admission; thus, it is essential for equity to be present in admission process ensuring equitable calibre students are enrolled who demonstrates ethical and outstanding success in their undergraduate programs. For this reason, it is essential to understand how universities equalize different curricula. Therefore, this paper is one such attempt at conducting a comparative study on a small group of universities in order to understand how each university perceives equity among different curricula.

\section{Literature Review \& Background Study}

\section{Importance of higher education:}

Knowledge and higher education are harmoniously co-related in local, national and global level. The emerging of higher education for the worldwide knowledge economy incorporated in many government policies, illustrates the universal importance of higher education. Besides the primary role of higher education towards economic development along with catering opportunities to individuals, it now extends to include promotion of trading, cultural diversity and political democracy. Higher education is a key driver of globalization. A strong co-relation has been illustrated between a country's global competitive performances with enrolment ratio of country's higher education. In his study, Marginson (2010) posited that the next great challenge to humanity is the construction of world society. To construct the world society, higher education and the exchange process of worldwide knowledge play a vital role.

\section{Perspective on higher education:}

In today's world, the purpose and value of a degree of higher education is debatable in comparison to 60 years back when it was associated to development of knowledge and skills training as illustrated by Knight (2020). 
Knight (2020) elaborates on her study about continuous reinventions associated in understanding the meaning of higher education to society and vice-versa. As such an in depth, analysis of historical trend of value of a higher education degree is established. This analysis helps us to understand different perspective on higher education. For instance, through the lens of liberal-humanist perspective, education viewed as an entitlement catering to personal empowerment and individual fulfilment. Furthermore, a preparation for employment is education; an idea that has been extensively emphasized originates from a constricted instrumental-perspective (Knight, 2020).

Elements of traditional higher education is illustrated through society's perspective on higher education. Introducing a class-laden concept in terms of associating higher education to formation of "well-rounded citizens". This concept is further illustrated when undergraduate degrees are shown as pathway to white-collar roles. Most importantly, to enter knowledge-based occupations, an individual's minimum initial education is the successful completion of undergraduate degree (Knight, 2020). The above elaborative perspectives on higher education sheds the light towards importance of higher education to economy and the reason for equity to be present in curriculum valuation to enter higher education to ensure that the students are well-versed in understanding of applicable norms and standards suggested in academic studies in a university.

\section{Accessibility \& inclusivity of higher education:}

UNESCO (2017) addresses admission entry requirements as a fundamental tool for establishing equity in higher education. Essentially, the importance of equity elaborated in terms of incorporating intermediary pathways between secondary school and higher education providing higher education access to everyone. In this process, UNESCO (2017) also discussed the engineering of admission requirements necessary for achieving equity objectives. This further emphasizes the importance of equitable measures to be present in admission criteria.

Accessibility and inclusivity of higher education, defined by the new fundamental elements set by Organization for Economic Co-operation and Development (OECD) are equality of right, equality of opportunity and equity. OECD defines a higher education is equitable based on an individual's innate ability and study effort as the only basis of evaluation to access, participate and obtain outcome from that higher education. This policy formed to disregard 19th century established norms when education was only accessible to an individual based on inherited elements: social class and gender. Thus, to avoid discrimination and establish equality of right Government Legislations steps in to govern policies in higher education (UNESCO, 2017). Similarly, in the United Arab Emirates, the Ministry of Education - Higher Education Affairs along with Commission of Academic Accreditation (CAA) governs the higher education policies.

Furthermore, in coordination with legislative measures of ensuring equity in higher education, benchmarking plays a key role. Benchmarking, a process of identifying best practices among organizations; now elaborated as a structural and strategic organization approach to compare, identify opportunities and improve. During the 190os, 
higher education adopted benchmarking to inculcate external evaluation structure, develop communication network among institutions and to bring about improvements. Benchmarking is defined as a conceptual collection of techniques and approaches similar to most practices. Internal benchmarking (one of the types) is suitable for operational functions within an organization. It incorporates many processes and one such is admissions related to hiring and assessment of student learning. This internal benchmarking provides a starting point to external benchmarking where comparison to similar organization takes place. Hence, in this research Table 1 reflects the benchmarking adopted in the context of setting admission criteria among universities in the United Arab Emirates. However, regardless of this benchmarking methodology, are the universities really comparing multiple curricula variation for admission criteria? Gary \& Sharron (2010) concludes their study stating the opportunity available to higher education for innovating their benchmarking. Hence, their conclusion portrays the necessity to bring about equitable and fair change to admission criteria.

\section{Importance of academic integrity in higher education:}

Higher education is addressed as a platform fundamental for lifelong learning. Traditionally, instillation of relatively advanced nature of intellectual activity has been through higher education (Reza Khan, 2014). Thus, her study accentuates the importance of academic integrity in higher education. Creation of responsible citizenship through academic integrity can help benefit greater society. Hence, developing academic integrity among students in higher education is crucial. As they eventually contribute in economic development ensuring greater society through knowledge, skill, research, intellectuality and ability. In academia, the code of conduct comprising moral and ethics is academic integrity (Reza Khan, 2014). Respect, responsibility, honesty, trust, fairness and courage are defined as fundamental values of academic integrity (ICAI, 2020). These values emphasize the necessity of establishing rigid and thorough academic integrity in higher education to eliminate any form of misconduct and produce high quality responsible citizenship. Thus, portraying the importance of academic integrity in higher education (Reza Khan, 2014).

\section{Importance of Admission Criteria}

Does the university have to meet the expectations of the students. . or is it the idea that the students grow to fit the expectations the university has of them? (Evans 1999, p. 10) (Lee, 2000, p. 12).

The above question, posited by Lee (2000) in her study about the correlation of higher education and employment portrays the norm of establishment and expectation of higher education to students and vice versa. However, Lee's (2000) study indicates towards development of critical and empowered learners is associated with teaching methodology reformation. What about the relationship between admission criteria catering to empowered learners as it is the very first step to university? The implications of admission criteria to students learning experience, as bringing multi-curricula students together under one umbrella is often unaddressed. 
Furthermore, the association of higher education to globalization results in extensive student mobility among nations. International students from a foreign nation also pursue a foreign national examination syllabus rather than the widely studied curricula mentioned in this research. Bista (2011) in his study states that academic misconduct is prevalent among international students in comparison to students who studied curriculum in English. Academic misconduct associated with previous learning attitude in school is an important reason. A comparison of Western education norm of understanding and application of concepts vs. non-Western education norms of memorization and rote learning has been mentioned to elaborate the reason that hinders smooth academic performance of international students in higher education. Since international students are accustomed to their cultural practices and norms, it is very difficult for them to adopt academic methods and techniques in higher education. Additionally, ineffective communication in terms of language barrier obstructing understanding of academic integrity associated guidelines such as importance of paraphrasing, citation, referencing contributes to academic misconduct by international students (Bista, 2011).

To address Bista's (2011) study on the barriers encountered by international student and their engagement of academic misconduct; Lee's (2000) question about university meeting expectation of student comes in the picture. Thus, highlighting the role admission criteria plays in this context and the important to establish proper valuation of admission criteria before admitting students from various curricula.

To this effect, the research objective of this study is to focus on the key role, admission criteria plays towards ensuring quality, integration, equity and success to prevail in higher education. Higher education is imperative in terms of providing opportunity and success for not only an individual but also world economy. Additionally, the contribution of higher education in building world society through exchange of cross-border knowledge; it is crucial for higher educational institutions to form equitable measures in admission criteria. This ensures that students of equal calibre with adequate knowledge has been converged supporting development of knowledge economy. Furthermore, the valuation of higher education in terms of creating individual empowerment and intellectuality development towards outstanding citizenship stresses the significant presence of equitable measures in all aspects of higher education. Nevertheless, this study further aims to elaborate the role of admission criteria in eliminating academic misconduct in higher education. Hence, ensuring professional, qualified and ethical citizens for greater good of society and global economic development.

\section{Methodology}

\section{Admission criteria used for qualitative analysis:}

Accessing secondary data from open-source mainly university websites, data from 5 universities was obtained. Local universities across the Emirates have been chosen which are accredited by Ministry of Education - Higher Education Affairs of the UAE. The admission criteria to undergraduate programs have been extracted and those data have been coded for qualitative analysis (table 1). Owen (2014) stipulates in his 
study about the use of qualitative analysis for research. Incorporating in his study interpretivism, a theoretical perspective in analyzing setting of the social world through derived interpretation of cultural and historical contexts. Max Weber (1948) emphasis the importance of interpretivism associated with study of human science. Owen's (2014) study focuses on understanding policy of a particular institution incorporating interpretivism. Similarly, for our research, admission criteria of different universities are analyzed to understand student integration and identify problem associated with inequity. Additionally, in our study, the concept of interpretivism plays a role as we analyze different school curriculum studied all around the world, which portrays interpretation of cultural context.

Furthermore, social constructivism has been utilized to qualitatively analyze our research of equity in admission. As Owen (2014) postulates in his study that constructivist paradigm is an important approach adopted by majority of researcher conducting qualitative research. Constructivism elaborates how human perspectives are used to understand the world. Owen (2014) adopted social constructive approach to understand the reality context and rules associated with the administrative function of his study. Likewise, in our research, data from secondary source have been extracted to analyze the actual context in reality associated with equity being present or absent in admission criteria. Through the use of social constructive approach, it can be seen in (Table 1) secondary data that the focused universities for this study incorporates similar admission criteria for each curriculum. This valuation of similar admission criteria helps us to understand equity in admission.

Additionally, document analysis is a vital component for any qualitative research (Owen, 2014). The process of systematically studying and assessing documents which exists either in printed or electronic form is known as document analysis. It creates platform for scrutinizing and interpreting elicit meaning of data similar to different analytical methods used in qualitative research. Document analysis provides indepth understanding which cater towards development of experiential knowledge. In qualitative research, document analysis is used as an independent method and some research exclusively relies on it (Bowen, 2009). For our research about equity in admission, document analysis of different university's admission criteria and the importance of equity has been incorporated to understand and identify gap in system causing distress among student community in society. The reliability of document analysis for this research is further illustrated through the use of "phenomenological reflection" technique which helps to produce important incidental themes such as absence of equity in admission across universities. Additionally, besides providing background knowledge, research scope and data supplement; documents also enable to track any variation or progress of an event used in the qualitative research (Bowen, 2009). "A university (any university) is in its documents rather than its buildings" (Owen, 2014, p. 10). This quote emphasizes the importance of formal policies of universities. In addition, documents are regarded as collective social products produced in social settings, a thought from Maw Weber's work Economy and Society (Owen, 2014). 


\section{Theoretical research of three curriculums:}

Additionally, a theoretical research of curriculum structure has been reviewed to juxtapose the following three curriculums: UK curriculum [Ordinary (O), Advance Subsidiary (AS) and Advanced (A) Level], Indian Curriculum [Central Board of Secondary Education (CBSE Grade - 12)] and Worldwide International Baccalaureate Diploma (IB).

The research methodology revolves around understanding the above-mentioned curriculums in evaluating the basis of set admission criteria for each curriculum. UK curriculum comprising of three different levels pursued from Grade - 10 to 13 in high school enables students to choose preferred number of subjects of their choice in each level. Usually, students opt to pursue a greater number of subjects in O Level compared to AS and A Level. A grading scheme of ( $A^{*}$ to $G$ ) is followed in UK curriculum (Department for Education, 2020). Comparatively, student's graduation from school with Indian Curriculum (CBSE) usually pursues minimum of 5 subjects with a percentile grading scheme for each subject out of 100 (CBSE Research \& Development Unit, 2012). Furthermore, briefly IB Diploma program incorporates 6 subject groups equally divided into higher and standard level categories along with core components: theory of knowledge (TOK), extended essay, creativity, action and service (CAS). A point system grading scheme is implemented in IB along with multiple requirements for awarding of Diploma. The highest point awarded is 45 in IB (International Baccalaureate Organization,2020).

\section{Results and Discussion}

\section{Importance of standardization of pre-university qualification}

Achieve (2007), a non-profit organization based in United States of America evoked the necessity of standardization of pre-university qualification to be modified and aligned with university academic requirements. The organization holds seminars and summits bringing multiple stakeholders (corporate CEOs, school and university leaders, governors etc.) under one umbrella representing the necessity of educational level alignment. Achieve (2007) evaluated the components of university admission test and standard placement test where the prior portrayed more effectiveness in student appraisal for admission generally. However, both the form of tests lacked elements of Achieve's criteria. This initiative of Achieve (2007) portrays the importance of proper benchmarked scrutinization of admission process and how the juxtaposition is established among different curriculums as stipulated in Table 1 (below).

In the context of the UAE, like Achieve (2007), Commission for Academic Accreditation and the Ministry of Education monitors the integrity, standard, assessment, certification and qualifications provided by private and public accredited universities. As such the entry requirements for admission to the both type of universities is set and monitored by the above-mentioned bodies (Godwin, 20o6). However, the in-depth analysis of how the entry requirements are set remains undefined which further contributes towards poor academic performance and engagement in academic misconduct by students coming from multi-curriculum pre-university backgrounds. 
The Ministry of Education and Commission of Academic Accreditation has been unsuccessful in monitoring and assuring quality of education provided by private high schools in the UAE posited in the research by Godwin (2006). This furthermore demonstrates the inequality present in student's pre-university knowledge and as such the question arises on the process of equalizing different curricula.

\section{Comparative analysis of admission criteria}

Comparative analysis of five local Ministry accredited universities in the UAE stipulated in Table 1 (below) show that the entry requirements for undergraduate university program for each curriculum is based on distinctive grades. Across the universities, the entry requirements for UK curricula remained consistent as opposed to CBSE and IB curriculum. However, IB Diploma of 24 points remained consistent among 4 out of 5 universities. In contrast to UK and IB curriculum, CBSE (Grade-12) portrayed fluctuations in grade requirement for admission to different universities. The range of grade requirements varied from $50 \%$ to $70 \%$.

Table 1

Comparative data of admission requirements across universities based in the United Arab Emirates.

\begin{tabular}{|c|c|c|c|c|c|}
\hline $\begin{array}{c}\text { Serial } \\
\text { no. }\end{array}$ & Emirates & University & $\begin{array}{c}\text { UK Curriculum } \\
\text { [O Level, AS Level \& A Level] }\end{array}$ & $\begin{array}{c}\text { Indian } \\
\text { Curriculum } \\
{[\text { CBSE }} \\
\text { Grade }-12] \\
\text { overall score }\end{array}$ & $\begin{array}{l}\text { IB } \\
\text { Diploma }\end{array}$ \\
\hline 1 & Dubai & A & $\begin{array}{l}\text { Combination of } \\
\text { O Level: } 5 \text { subjects } \\
\text { As or A Level: } 2 \text { subjects with a minimum } \\
\text { of } C \text { grade for each subject. }\end{array}$ & $70 \%$ & 24 points \\
\hline 2 & Dubai & B & $\begin{array}{l}\text { Minimum } 7 \text { subjects with grade: } 3 \text { B's and } \\
4 \text { C's from - (O) Levels, AS Levels and/or A } \\
\text { Levels. }\end{array}$ & $55 \%$ & 26 points \\
\hline 3 & Abu Dhabi & C & $\begin{array}{l}\text { Five (5) subjects in the O level with } \\
\text { minimum grade E or above in each subject. } \\
\text { Two (2) subjects in Advance Subsidiary } \\
\text { Level with min. D or above in each subject. } \\
\text { One (1) subject in the Advanced Level } \\
\text { with min. D or above. }\end{array}$ & $50 \%$ & 24 points \\
\hline 4 & Sharjah & $\mathrm{D}$ & $\begin{array}{l}\text { The highest } 7 \text { grades obtained will be } \\
\text { considered as follows: } \\
\text { A minimum grade of } C \text { in } 5 \text { O-Level } \\
\text { subjects, and minimum grade of D in } 2 \\
\text { AS-Level subjects or } \\
\text { A minimum grade of } C \text { in } 6 \text { O-Level } \\
\text { subjects and a minimum grade of } E \text { in one } \\
\text { A-Level subject. }\end{array}$ & $70 \%$ & 24 points \\
\hline 5 & Fujairah & $\mathrm{E}$ & $\begin{array}{l}\text { (7) seven subjects at O' level with a } \\
\text { minimum grade of C in each subject. If a } \\
\text { subject is taken at the AS Level or A Level } \\
\text { the required minimum score is reduced to } \\
\text { D and E }\end{array}$ & $55 \%$ & 24 points \\
\hline
\end{tabular}

Source: official websites of five universities, which are open sources of information to public. 
However, the question arises as to how this comparison has been established. Theoretical research analysis of curriculum content, structure, examination and grading of each curriculum portrayed distinction and individuality across them. Therefore, this further stimulates the condition that there is inequity in admission portraying the absence of academic integrity value integrated in admission process across universities.

An empirical study regarding the importance of high school grades over placement tests such as SAT towards determining college graduation, GPA, etc. depicted in the research of (Gala et al., 2019) indicates the importance of equalizing different curricula for the basis of university admission.

There exists insufficient research and thought towards the base line criteria which compares, for instance, $70 \%$ CBSE Grade -12 grades is equivalent to IB points: 24 . How two completely distinctive curriculum grade margins are equivalent for students to pursue admission for same program? This question further provides platform to evaluate the unfairness and unawareness present in valuation of high school curriculum assessment for admission purposes across the universities, which could be setting students to disadvantage in the classroom.

\section{Conclusions}

The qualitative analysis of five local accredited universities in the UAE portrayed the importance of proper curriculum valuation of different high school curriculums as a basis of admission to universities. The existence of complete distinctive components in terms of structure, content, marking criteria, examination methodology arises the question of equity present in admission process. There exists no research on this topic; thus, creating the platform of further investigation and possible solution in bringing about equity in admission.

This study is the first such attempt, paving way for possible solutions and equivalent benchmarked criteria for valuation of high school curriculum enabling effective establishment of integrity among students from multiple pre-university curriculum background through transparent, standardized entrance requirement.

\section{Recommendations}

The absence of consideration of curriculum contents, structure, style of examination and learning outcomes depicts the importance of identification of structured valuation guidelines towards setting admission criteria. A possible and quick solution could be implementation of worldwide-standardized placement examination, but this test only evaluates the cognitive ability of a student, which is insufficient for student appraisal for admission (Gala et al., 2019).

\section{References}

Achieve, I. W. D. (2007). Aligned Expectations? A Closer Look at College Admissions and Placement Tests. Achieve, Inc. Retrieved from https://search-ebscohost-com.ezproxy.uow. edu.au/login.aspx? direct $=$ true $\& d b=$ eric $\& A N=E D 496080 \&$ site $=$ eds - live 
Aidoo-Buameh, J., \& Ayagre, P. (2013). The Effect of Entry Grades on Academic Performance of University Accounting Students: A Case of Undergraduates of Central University College. Research Journal of Finance and Accounting, 4(7), 198-207.

ANNA ZimDARs. (2010). Fairness and undergraduate admission: a qualitative exploration of admissions choices at the University of Oxford. Oxford Review of Education, 36(3), 307. https://doi-org.ezproxy.uow.edu.au/10.1080/03054981003732286

Atkinson, D., Zaung NaU, S., \& Symons, C. (2016). Ten Years in the Academic Integrity Trenches: Experiences and Issues. Journal of Information Systems Education, 27(3), 197-207.

Atkinson, R. C., Geiser, S., \& University of California, B. C. For S. in H. E. (2009). Reflections on a Century of College Admissions Tests. Research \& Occasional Paper Series: CSHE.4.o9. Center for Studies in Higher Education. Retrieved from https://search-ebscohost-com.ezproxy.uow.edu.au/ login. aspx ?direct=true\&db=eric\&AN=ED507062\& ite=eds - live

BisTA, K. K. (2011). 12: Academic Dishonesty among International Students in Higher Education. To Improve the Academy, 3o(1), 159.

Bowen, G. A. (2009). Document Analysis as a Qualitative Research Method. Qualitative Research Journal (RMIT Training Pty Ltd Trading as RMIT Publishing), 9(2), 27-40.

https://doi-org.ezproxy.uow.edu.au/10.3316/QRJo902027

CBSE Research \& Development Unit. (2012). Curriculum for the Academic Year 2019-20. Central Board of Secondary Education: http://cbseacademic.nic.in/index.html

Department FOr EducATION, O. A. (2020). Curriculum and qualifications. GOV.UK: https://wWw.gov.uk/topic/schools-colleges-childrens-services/curriculum-qualifications

Galla, B. M., Shulman, E. P., Plummer, B. D., Gardner, M., Hutt, S. J., Goyer, J. P., \& Duckworth, A. L. (2019). Why High School Grades Are Better Predictors of On-Time College Graduation Than Are Admissions Test Scores: The Roles of Self-Regulation and Cognitive Ability. AMERICAN EDUCATIONAL RESEARCH JOURNAL, 56(6), 2077-2115. https://doi-org.ezproxy.uow.edu.au/10.3102/0002831219843292

GODWIN, M. S. (2006). GLOBALIZATION, EDUCATION AND EMIRATISATION: A STUDY OF THE UNITED ARAB EMIRATES. The Electronic Journal of Information Systems in Developing Countries, 27(1), 1-14.

Gudo, C. O., \& Olel, M. A. (2011). Students' Admission Policies for Quality Assurance: Towards Quality Education in Kenyan Universities. International Journal of Business and Social Science, 2(8), 177-183. http://www.ijbssnet.com/journals/Vol._2_No._8\%3B_May_2011/22.pdf

Harding, T. S., Carpenter, D. D., \& Finelli, C. J. (\& others). (2004). Does Academic Dishonesty Relate to Unethical Behavior in Professional Practice? An Exploratory Study. Science and Engineering Ethics, $10(2), 311-324$.

ICAI. (2020). Fundamental Values of Academic Integrity. International Center for Academic Integrity. Retrieved from www.academicintegrity.org: https://wWw. academicintegrity.org/fundamental-values/

International Baccalaureate Organization. (2020). Diploma Programme. ibo.org: ibo.org/programmes/diploma-programme/

KNIGHT, E. (2020). Tracing the changing value of higher education through English prospectuses 1976-2013. HIGHER EDUCATION RESEARCH \& DEVELOPMENT, 39(1), 141-155. https://doi-org.ezproxy.uow.edu.au/10.108o/o7294360.2019.1681373

LeE Harvey. (200o). New Realities: The Relationship between Higher Education and Employment. Tertiary Education \& Management, 6(1), 3-17. https://doi-org.ezproxy.uow.edu.au/10.1080/13583883.2000.9967007 
Levy, G. D., \& Ronco, S. L. (2012). How Benchmarking and Higher Education Came Together. New Directions for Institutional Research, 156, 5-13.

Marginson, S. (2010). Higher Education in the Global Knowledge Economy. Procedia - Social and Behavioral Sciences, 2(5), 6962-6980.

https://doi-org.ezproxy.uow.edu.au/10.1016/j.sbspro.2010.05.049

Mattern, K., Radunzel, J., Bertling, M., \& Ho, A. D. (2018). How Should Colleges Treat Multiple Admissions Test Scores? Educational Measurement: Issues and Practice, 37(3), 11-23. Retrieved from https://search-ebscohost-com.ezproxy.uow.edu. au/login. aspx?direct=true\&db=eric\&AN= EJ1191362\&site=eds - live

OWEN, G. T. (2014). Qualitative methods in higher education policy analysis: Using interviews and document analysis. Qualitative Report, 26, 19p.

REZA KHAN, Z. (2014). Developing a factor-model to understand the impact of factors on higher education students' likelihood to e-cheat. School of Information Systems and Technology.

Santelices, M. V., Horn, C., \& CatalÁn, X. (2019). Institution-Level Admissions Initiatives in Chile: Enhancing Equity in Higher Education? Studies in Higher Education, 44(4), 733-761. Retrieved from https://search-ebscohost-com. ezproxy.uow.edu. au/login. aspx?direct=true\&db=eric\&AN= EJ1209610\&site=eds - live

Tabsh, Sami, El Kadi, Hany, \& Abdelfatah, Akmal. (2015). Past and Present Engineering Students' Views on Academic Dishonesty at a Middle-Eastern University. International Journal of Engineering Education, 31(5), 1334-1342.

UNESCO. IIEP [3376] (2017). Six ways to ensure higher education leaves no one behind. UNESDOC Digital library [Online]. 4-5. Available: https://unesdoc. unesco.org/ark:/48223/pfoooo247862

Wilkins, S. (2010). Higher Education in the United Arab Emirates: An Analysis of the Outcomes of Significant Increases in Supply and Competition. Journal of Higher Education Policy and Management, 32(4), 389-400. Retrieved from https://search-ebscohost-com.ezproxy.uow.edu.au/login.aspx? direct=true\&db=eric\&AN=EJ892316\&site=eds -1 ive

Williams, S., TAnner, M., \& BeARD, J. ET AL. (2014). Academic Misconduct among Business Students: A Comparison of the US and UAE. Journal of Academic Ethics, 12(1), 65-73. Retrieved from https://search-ebscohost-com. ezproxy.uow. edu. au/login. aspx?direct=true\&db=pif\&AN= PHL2219698\&site=eds - live

\section{Authors}

Salma Sadia Rakhman, University of Wollongong in Dubai FZ-LLC UOWD Building, Dubai Knowledge Park Dubai, United Arab Emirates, P.O. Box 20183, e-mail: salma.sadia.rakhman@gmail.com

Dr Zeenath Reza Khan, University of Wollongong in Dubai FZ-LLC UOWD Building, Dubai Knowledge Park Dubai, United Arab Emirates, P.O. Box 20183, e-mail: zeenath.khan@gmail.com 